\title{
„Krankenhäuser sind ideale Orte, um Tötungen zu kaschieren"
}

Wie kann es geschehen, dass eine Pflegekraft serienweise Patienten tötet? Dieser Frage geht Prof. Karl H. Beine vom St. Marien-Hospital Hamm seit vielen Jahren nach. In dem Buch „Krankentötungen in Kliniken und Heimen“, das jetzt in überarbeiteter Auflage* erschienen ist, hat er 36 Tötungsserien analysiert.

MMW: Sie beschreiben sieben Tötungsserien, die von 1975 bis 2008 in deutschen Heimen und Kliniken aufgedeckt wurden. Sind diese Taten möglicherweise nur die Spitze des Eisbergs?

Beine: In der allgemeinen Kriminologie geht man davon aus, dass auf ein aufgedecktes Tötungsdelikt drei nicht aufgedeckte entfallen. In Krankenhäusern und Heimen, in denen ja auch unter normalen Umständen gestorben wird, dürften qualifizierte Aussagen zum Dunkelfeld besonders schwierig sein. Auch die Tatwerkzeuge, meist Medikamente, werden ja üblicherweise verwendet. Der Tötungshergang sieht ebenfalls zunächst häufig aus wie eine normale pflegerische Verrichtung. Es gibt in dieser Hinsicht keinen idealeren Ort als Krankenhäuser und Heime, um eine vorsätzliche Tötung zu kaschieren.

MMW: Besonders verstörend ist, dass ausgerechnet Menschen, die sich der Linderung von Leiden verschrieben haben, hilflose Kranke töten. Was treibt sie dazu? Beine: Die meisten der Täter/innen haben ihren Beruf wegen des hohen Sozialprestiges von Gesundheitsberufen ergriffen - um sich selbst besser zu fühlen. Wenn diese Wertschätzung ausbleibt und private und berufliche Konflikte dazukommen, trägt die ursprüngliche Motivlage nicht mehr. Auf dem Weg der projektiven Identifikation übertragen sie ihr eigenes Leiden auf den Patienten. Dann töten sie einen fremden Menschen in der-fehlerhaften - sicheren Gewissheit, ihn damit, erlöst'zu haben.

MMW: Mit welchen Methoden wurde getötet?

Beine: Die Tötungen waren zum Teil so ultrabrutal, dass ein stundenlanger Todeskampf stattgefunden hat. In den meisten Fällen wurde der Tod durch Medikamente herbeigeführt, Blutdruckmittel, Muskelrelaxanzien, Opiate, Narkotika. Einige Patienten wurden erstickt. Ein Pfleger hat bis zu zehnmal 20-ml-Spritzen mit Luft in die Vene injiziert. Bei der im Täterjargon „Mundpflege" genannten Tötungsmethode wurde den Patienten mit einem Spatel der Zungengrund nach unten gedrückt und dann Wasser eingeflößt.

MMW: Waren die Opfer denn in besonderem Maß moribund?

Beine: Nein. Bei allen Opfern war der Zeitpunkt des Sterbens überraschend.

MMW: Sind die Täter/innen als psychisch krank einzustufen?

Beine: Keiner war psychisch so sehr gestört, dass er nicht gewusst hätte, was er tut. In Deutschland wurde bisher nur einem Pfleger verminderte Schuldfähigkeit zuerkannt.

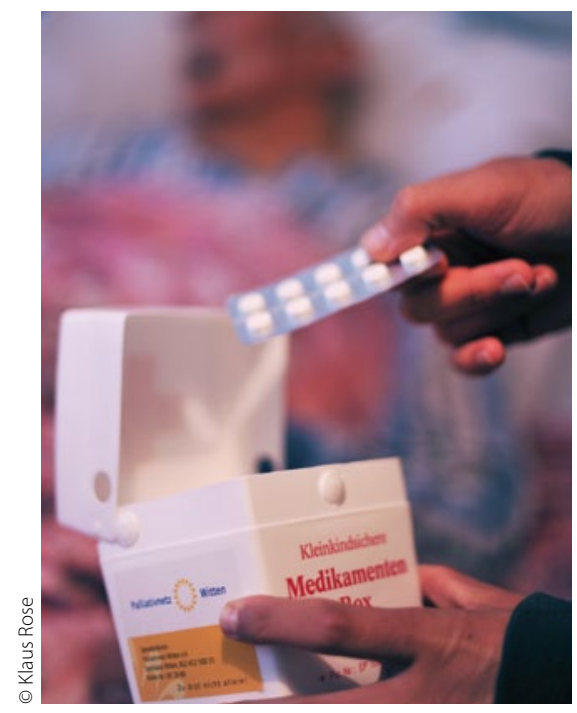

Meist wurde mit Medikamenten getötet.

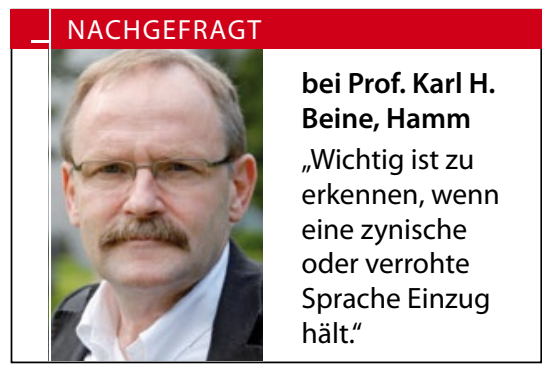

MMW: Welche Rolle spielt die Arbeitssituation?

Beine: Solche Krankentötungen haben auch in Einrichtungen stattgefunden, in denen die Arbeitsbelastung nicht hoch war. Trotzdem gibt es bei entsprechend disponierten Tätern ungünstige Einflussfaktoren am Arbeitsplatz, z. B. wenn Regeln über Jahre hinweg missachtet werden, ohne dass die Vorgesetzten reagieren, und ein Egal-Klima entsteht. Oft wurde die Vergabe unverordneter Medikamente toleriert, Dokumentationspflichten wurden vernachlässigt oder ein verrohter, gewalttätiger Umgang mit Patienten blieb ohne kritische Rückmeldung.

MMW: Haben Patiententötungen auch etwas mit gesellschaftlichen Fehlentwicklungen zu tun, z. B. der Verdrängung von Alter, Siechtum und Tod?

Beine: Ja, erheblich. Die Täter dürfen sich ja als heimliche Vollstrecker des gesellschaftlichen Mehrheitswillens fühlen, solange über ,Rentnerschwemme, , Altenberge' und ,Kostenfaktoren auf zwei Beinen' geredet wird. Eine Täterin hat vor kurzem noch in einem Interview gesagt, dass sie hofft, dass die Verantwortlichen einmal sehen, dass das, was sie getan hat, eigentlich das Richtige war.

MMW: Sie berichten, dass Alarmsignale meist ignoriert wurden. Was sind Warnzeichen?

Beine: Aussagen wie "morgen lebt der nicht mehr" sind besonders in Kombination mit Fehlbeständen bei Medikamenten oder sozialem Rückzug des Mitarbeiters alarmierend. Wichtig ist auch zu erkennen, wenn eine zynische und verrohte Sprache Einzug hält. Fast alle Täter hatten im Vorfeld sogar schon einschlägige Spitznamen wie, Vollstrecker' oder, Killer-Joe.'

- Interview: Dr. Beate Schumacher

- Karl H. Beine. Krankentötungen in Kliniken und Heimen. Aufdecken und verhindern. 2., überarbeitete Auflage 2011, ISBN 978-3-7841-2059-1. 